\title{
Low-Temperature Thermolysis Behavior of Tetramethyl- and Tetraethyldistibines
}

\author{
Naoufal Bahlawane, ${ }^{a}$ Frank Reilmann, ${ }^{\text {a }}$ Stephan Schulz, \\ Daniella Schuchmann, ${ }^{b}$ and Katharina Kohse-Höinghaus ${ }^{a}$ \\ ${ }^{a}$ Department of Chemistry, Bielefeld University, Bielefeld, Germany \\ ${ }^{\mathrm{b}}$ Inorganic Chemistry, Duisburg-Essen University, Essen, Germany
}

The thermolysis behavior of tetramethyl- and tetraethyldistibine $\left(\mathrm{Sb}_{2} \mathrm{Me}_{4}\right.$ and $\left.\mathrm{Sb}_{2} \mathrm{Et}_{4}\right)$ was investigated using a mass spectrometer coupled to a tubular flow reactor under near-chemical vapor deposition (CVD) conditions. $\mathrm{Sb}_{2} \mathrm{Me}_{4}$ undergoes a gas-phase disproportionation with an estimated activation energy of $163 \mathrm{~kJ} / \mathrm{mol}$. This reaction leads to the formation of methylstibinidine, $\mathrm{SbMe}$, that reacts on the surface to produce antimony film and $\mathrm{SbMe}_{3}$. Unfortunately, this clean decomposition pathway is limited to a narrow temperature range of $300-350^{\circ} \mathrm{C}$. At temperatures exceeding $400^{\circ} \mathrm{C}, \mathrm{SbMe}_{3}$ decomposes following a radical route with a consequent risk of carbon contamination. In contrast, $\mathrm{Sb}_{2} \mathrm{Et}_{4}$ disproportionates at the hot wall of the reactor. According to mass-spectrometric data, this reaction is significant starting at a temperature of $100{ }^{\circ} \mathrm{C}$, with an apparent activation energy of $104 \mathrm{~kJ} / \mathrm{mol}$. Within the temperature range of $100-250{ }^{\circ} \mathrm{C}$, the precursor decomposition leads to the formation of antimony films and $\mathrm{SbEt}_{3}$, whereas different molecular reaction pathways are significantly activated above $250^{\circ} \mathrm{C}$. The use of $\mathrm{Sb}_{2} \mathrm{Et}_{4}$ lowers the risk of carbon contamination compared to $\mathrm{Sb}_{2} \mathrm{Me}_{4}$ at high temperature. Therefore, $\mathrm{Sb}_{2} \mathrm{Et}_{4}$ is a promising CVD precursor for the growth of antimony films in the absence of hydrogen atmosphere in a wide temperature range. (J Am Soc Mass Spectrom 2008, 19, 1336-1342) () 2008 American Society for Mass Spectrometry

A ntimony-containing compounds are extensively investigated as thermoelectric [1, 2], lasing [3], photo-detecting [4], magnetic [5, 6], and transparent electrode [7] materials for a wide range of applications. Most of the antimony-containing materials possess metastable compositions that impose low processing temperatures. Chemical vapor deposition (CVD) is considered as a nearly ideal, low-cost, and high throughput approach for device manufacturing; however, its application here is hindered by the lack of suitable, low-temperature antimony precursors [8]. Standard antimony precursors including $\mathrm{SbMe}_{3}$ and $\mathrm{SbEt}_{3}$ exhibit high thermal stability, which complicates the growth of materials such as $\operatorname{InSb}[9,10]$. These precursors were therefore judged not suitable as controllable antimony sources because of their strong $\mathrm{Sb}-\mathrm{C}$ bond [11, 12]. The strength of the $\mathrm{Sb}-\mathrm{C}$ bond was found to decrease with increasing ligand size [13], although the extremely low volatility of the resulting molecules represents a significant drawback [14]. Deuterated stibine $\left(\mathrm{SbD}_{3}\right)$ was proposed by Todd et al. [8] as a suitable carbon-free antimony source that allows deposition of antimony films at temperatures as low as $200^{\circ} \mathrm{C}$. $\mathrm{SbD}_{3}$ shows an enhanced stability compared to that of $\mathrm{SbH}_{3}$ at $23^{\circ} \mathrm{C}$, which allows its implementation as a CVD

Address reprint requests to Dr. Naoufal Bahlawane, Bielefeld University, Physical Chemistry Department, Universitätsstr. 25, 33615 Bielefeld, Germany. E-mail: naoufal@pc1.uni-bielefeld.de precursor [8]. Tetramethyl- and tetraethyldistibine $\left(\mathrm{Sb}_{2} \mathrm{Me}_{4}\right.$ and $\left.\mathrm{Sb}_{2} \mathrm{Et}_{4}\right)$ were also investigated as alternative precursors $[11,12,15]$. These showed low decomposition temperatures without carbon retention and enabled an accurate control of doping concentration as a result of the conveniently controllable vapor pressures. Dickson et al. [11] reported on the decomposition of $\mathrm{Sb}_{2} \mathrm{Me}_{4}$ at $300^{\circ} \mathrm{C}$ in the presence of molecular hydrogen to yield pure antimony films, but no information was given on the kinetics or on the nature of the obtained decomposition products. A successful growth of InSb was demonstrated at $330^{\circ} \mathrm{C}$ using $\mathrm{Sb}_{2} \mathrm{Et}_{4}$ in combination with $\mathrm{InMe}_{3}$ [11]. In this case the deposition kinetics was limited by the cracking efficiency of $\mathrm{InMe}_{3}$. The low deposition temperature $\left(330^{\circ} \mathrm{C}\right)$ suppresses reaction at the hetero-interface for the growth of heterojunctions and superlattices.

In this study, the decomposition mechanism of two selected distibine compounds will be investigated with the objective to clarify the mechanism that is responsible for the low resulting deposition temperature and to evaluate the contamination risk as a function of the deposition temperature.

\section{Experimental}

$\mathrm{Sb}_{2} \mathrm{Me}_{4}$ [16] and $\mathrm{Sb}_{2} \mathrm{Et}_{4}$ [17] were prepared according to literature methods. Thermolysis reactions were investigated in a stainless steel tubular hot-wall reactor at 
$1-1.6 \times 10^{-5}$ mbar, whereas the precursor was delivered from an evaporator maintained at 0 and $25{ }^{\circ} \mathrm{C}$ for $\mathrm{Sb}_{2} \mathrm{Me}_{4}$ and $\mathrm{Sb}_{2} \mathrm{Et}_{4}$, respectively, using $2 \mathrm{sccm}$ of argon as carrier gas. The operating pressure range corresponds to conditions where GaSb was grown by CVD in earlier work $[18,19]$. The residence time of gaseous molecules was estimated to be $<70 \mu \mathrm{s}$. The tubular reactor has a high surface-to-volume ratio $(\mathrm{S} / \mathrm{V}=0.5$ $\mathrm{mm}^{-1}$ ), which favors surface-gas interactions. A copper skimmer was used to extract a gas sample from the pyrolysis reactor to the ionization chamber, which is pumped down to $<5 \times 10^{-6}$ mbar. The sampled gas is then subjected to electron-impact ionization before analysis with a time-of-flight mass spectrometer (Kaesdorf, Munich, Germany), equipped with a reflectron. The mass resolution of this instrument is $\mathrm{m} / \Delta \mathrm{m}=4000$ and the sensitivity is better than $10 \mathrm{ppm}$ for most considered hydrocarbons in this study. The energy of the electron beam is tunable between 5 and $40 \mathrm{eV}$, and analysis with 10 and $20 \mathrm{eV}$ was routinely used to minimize electronic fragmentation and to allow its discrimination from the thermally induced reactions. Setting the electron beam energy at nominally $10 \mathrm{eV}$ allows minimizing the electron-induced fragmentation, although without completely succeeding to suppress it because of the energy spread of about $0.5 \mathrm{eV}$ (full width at half-maximum).

\section{Results and Discussion}

Mass spectrometry was repeatedly used to support and to improve the understanding of the CVD process. Our previous work demonstrated its usefulness for the systematic evaluation of new families of CVD precursors [20], for the identification of the occurring reaction pathways under near-CVD conditions and for the determination of their activation energies [21]. Both precursors investigated in this study are highly volatile at $18{ }^{\circ} \mathrm{C}$ with partial pressures of $0.32 \mathrm{mbar}$ for $\mathrm{Sb}_{2} \mathrm{Me}_{4}$ and $0.8 \times 10^{-3}$ mbar for $\mathrm{Sb}_{2} \mathrm{Et}_{4}$ [11]. These compounds are also air-sensitive [22], which imposes careful handling under controlled atmosphere. Furthermore, $\mathrm{Sb}_{2} \mathrm{Et}_{4}$ is lightsensitive, indicating its higher reactivity [11].

\section{Tetramethyldistibine}

Figure 1 shows the recorded mass spectra at different temperatures. At $20^{\circ} \mathrm{C}$, the molecular ion peak presents the highest intensity. The degree of electron-induced fragmentation is very low, either leading to the loss of methyl groups with subsequent formation of $\mathrm{Sb}_{2} \mathrm{Me}_{3}$ and $\mathrm{Sb}_{2} \mathrm{Me}_{2}$ fragment ions, or to the scission of the $\mathrm{Sb}-\mathrm{Sb}$ bond to form $\mathrm{SbMe}_{2}$ fragment ion. The spectrum at $400{ }^{\circ} \mathrm{C}$ shows that the signals representing the precursor are substantially decreased, except for that corresponding to the $\mathrm{SbMe}_{2}$ fragment ion, and that peaks attributed to $\mathrm{SbMe}_{3}$ and $\mathrm{SbMe}$ have emerged. The reference spectrum of $\mathrm{SbMe}_{3}$ below the temperature decomposition threshold exhibits the molecular peak signals

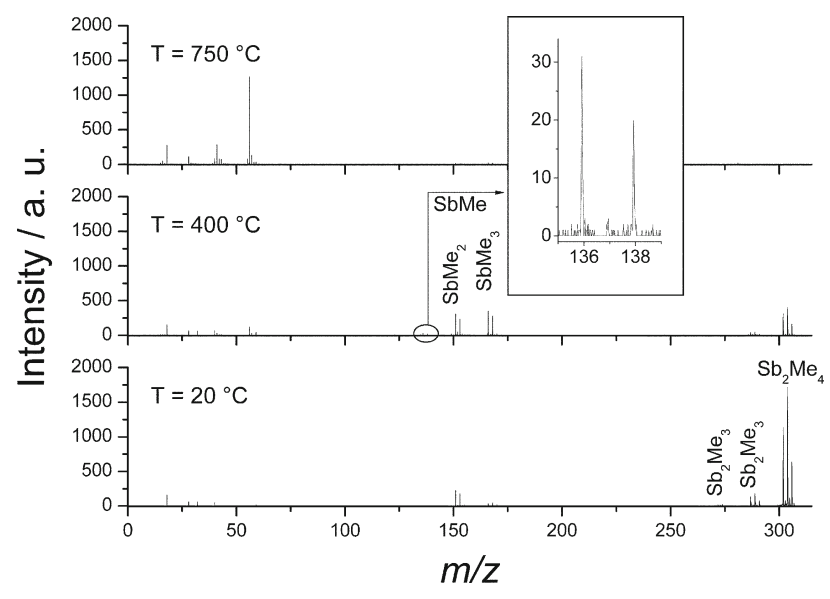

Figure 1. Mass spectra of $\mathrm{Sb}_{2} \mathrm{Me}_{4}$ collected after ionization with a $10 \mathrm{eV}$ electron beam, CVD reactor at 20,400 , and $750{ }^{\circ} \mathrm{C}$.

(highest intensity) in addition to signals arising from the electronic fragmentation with the loss of one methyl group. In this reference spectrum (available as supplementary materials, which can be found in the electronic version of this article), no signal could be attributed to $\mathrm{SbMe}$ fragment ion. Therefore, the increase of the $\mathrm{SbMe}_{2}$ signal at $400{ }^{\circ} \mathrm{C}$ can be attributed to the formation of $\mathrm{SbMe}_{3}$ whereas methylstibinidine (SbMe) is considered as a second product of the thermolysis reaction.

At the reactor temperature of $750{ }^{\circ} \mathrm{C}_{,} \mathrm{C}_{4^{-}}, \mathrm{C}_{3^{-}}, \mathrm{C}_{2^{-}}$, and $\mathrm{C}_{1}$-species are detected, indicating the complete precursor thermolysis. Butene $\left(\mathrm{C}_{4} \mathrm{H}_{8}\right)$ was identified as the major product of thermolysis at $750{ }^{\circ} \mathrm{C}$, as clearly shown in the supplementary materials. The trend of individual peaks was presented as a function of the thermolysis temperature in Figure 2 for the most relevant species. The precursor molecule, represented by the peaks attributed to $\mathrm{Sb}_{2} \mathrm{Me}_{4}$ and its fragment ions $\mathrm{Sb}_{2} \mathrm{Me}_{3}$ and $\mathrm{Sb}_{2} \mathrm{Me}_{2}$ in Figure 2a, shows good stability up to a reactor temperature of $300^{\circ} \mathrm{C}$. Above this temperature, an abrupt decay was observed with a complete depletion starting at $450{ }^{\circ} \mathrm{C}$. The thermolysis of $\mathrm{Sb}_{2} \mathrm{Me}_{4}$ was associated with the detection of $\mathrm{SbMe}_{3}$ as dominant product, in terms of signal intensity, and $\mathrm{SbMe}$ as shown in Figure $2 \mathrm{~b}$. Figure $2 \mathrm{c}$ shows that $\mathrm{SbMe}_{2}$ signal can be fitted with a sum of a decay component at $300^{\circ} \mathrm{C}$, corresponding to the precursor molecule, and to a peak with a maximum above $400{ }^{\circ} \mathrm{C}$, which corresponds to the formation of $\mathrm{SbMe}_{3}$. Therefore, the detection of $\mathrm{SbMe}_{2}$ ion is reasonably attributed to the fragmentation of $\mathrm{SbMe}_{3}$ and $\mathrm{Sb}_{2} \mathrm{Me}_{4}$.

The detection of $\mathrm{SbMe}_{3}$ and $\mathrm{SbMe}$ molecules in the gas phase suggests the occurrence of an intramolecular disproportionation reaction as presented in Scheme 1. The activation energy of this reaction was estimated at $(163 \pm 4) \mathrm{kJ} / \mathrm{mol}$ from the decay of the molecular peak when assuming a first-order kinetics with $\mathrm{A}=10^{13} \mathrm{~s}^{-1}$ as the preexponential factor.

The low intensity of the peaks attributed to SbMe (Figure 1) and its early depletion (Figure 2b) hint at its 

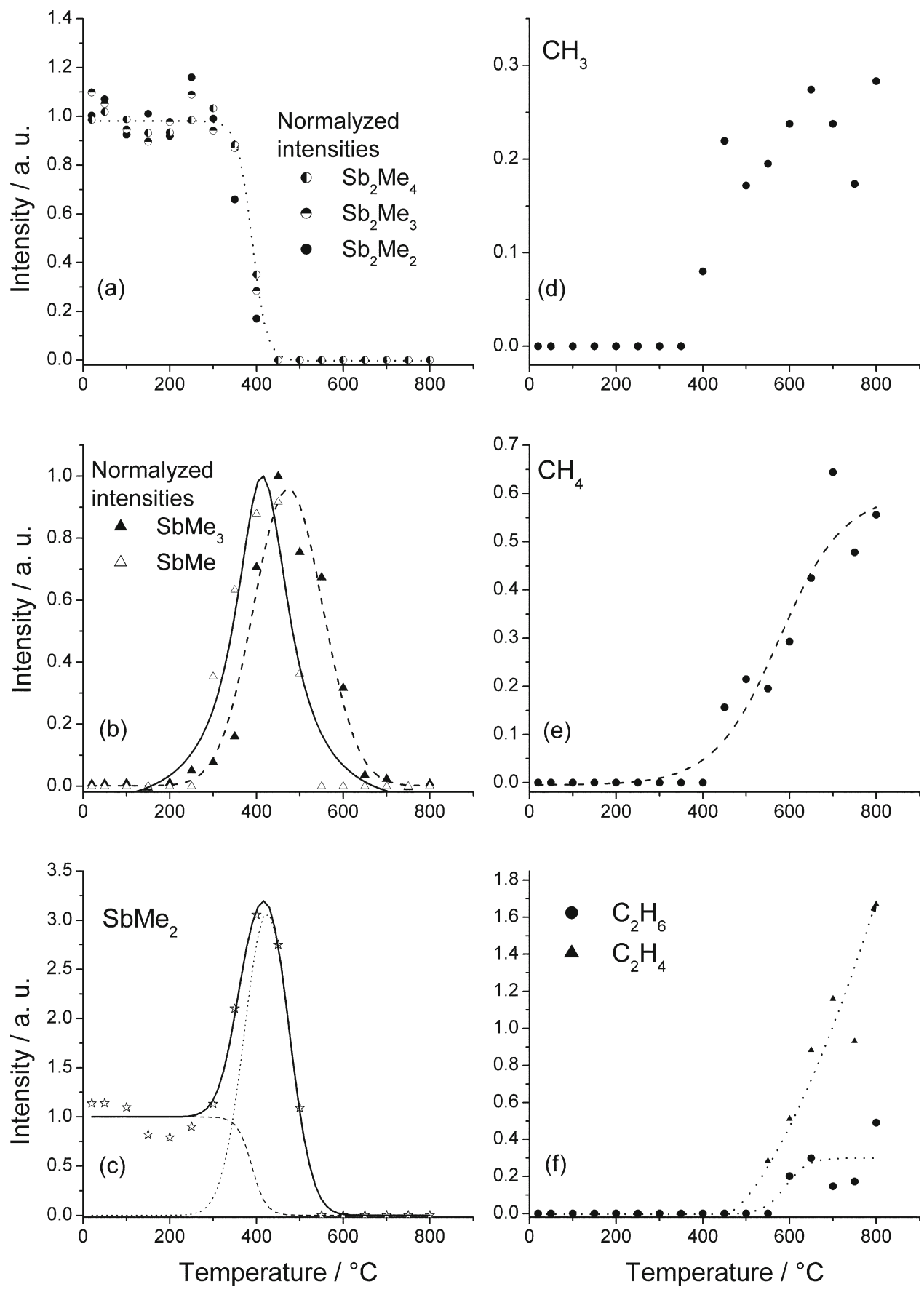

Figure 2. Temperature-dependent intensity of relevant species in the thermolysis of $\mathrm{Sb}_{2} \mathrm{Me}_{4}$.

further reaction, probably on the wall of the reactor. This reaction is expected to result in the formation of an antimony deposit in addition to a methyl radical, which the profile is depicted as a function of the temperature in Figure 2d. The significant formation of methane (Figure 2e), starting at a temperature of $400{ }^{\circ} \mathrm{C}$ indicates

\section{$\mathrm{Sb}_{2} \mathrm{Me}_{4} \longrightarrow \mathrm{SbMe}+\mathrm{SbMe}_{3}$}

Scheme 1 hydrogen abstraction from adjacent methyl ligands, probably on the surface where coating occurs. Several higher hydrocarbons have been detected above $500{ }^{\circ} \mathrm{C}$, including butane, butene, propane, ethane, and ethene, from which ethane and ethene are shown in Figure $2 \mathrm{f}$. At temperatures exceeding $600{ }^{\circ} \mathrm{C}$, hydrogen and several unsaturated hydrocarbons were detected. These observations indicate the presence of several pathways with a high risk of carbon contamination in the case of the growth of antimony films from the thermolysis of $\mathrm{Sb}_{2} \mathrm{Me}_{4}$ at temperatures exceeding $400{ }^{\circ} \mathrm{C}$. 


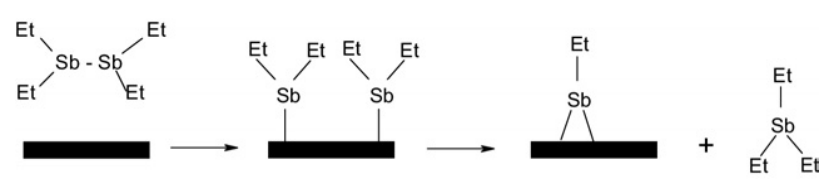

Scheme 2

Comparing the mass-spectroscopic results obtained for $\mathrm{Sb}_{2} \mathrm{Me}_{4}$ and $\mathrm{SbMe}_{3}$ shows an advantageous low temperature $\left(\sim 300^{\circ} \mathrm{C}\right)$ and slightly lower activation energy $(163 \mathrm{~kJ} / \mathrm{mol})$ of the decomposition process for $\mathrm{Sb}_{2} \mathrm{Me}_{4}$. In fact, $\mathrm{SbMe}_{3}$ was reported to significantly decompose at a temperature of $400{ }^{\circ} \mathrm{C}[23,24]$, with an activation energy of $171 \mathrm{~kJ} / \mathrm{mol}$ [25]. The decomposition products of $\mathrm{Sb}_{2} \mathrm{Me}_{4}-\mathrm{SbMe}$ and $\mathrm{SbMe}_{3}$-are already observed at $300{ }^{\circ} \mathrm{C}$, which is in agreement with the early investigation by Dickson et al. [11], who reported on the growth of $\mathrm{Sb}$ films at $300{ }^{\circ} \mathrm{C}$ from this precursor in the presence of hydrogen.

Within the narrow temperature range of $300-350^{\circ} \mathrm{C}$, no hydrocarbon products were detected as depicted in the temperature-dependent profiles in Figure 2, whereas a significant fraction of the precursor has already decomposed, which might be attributed to the deposition of antimony forming exclusively $\mathrm{SbMe}_{3}$ as product. The ligand exchange between adsorbed $\mathrm{SbMe}$ is assumed to form $\mathrm{SbMe}_{3}$ that can desorb from the surface in addition to the formation of an antimony deposit. The increase of the rate of this reaction with increasing temperature leads to the depletion of SbMe from the gas phase. It is anticipated that the growth of carbon-free antimony films can be expected in this temperature range (300$350{ }^{\circ} \mathrm{C}$ ) also in the absence of molecular hydrogen. To date, this was demonstrated only in the presence of molecular hydrogen by Dickson et al. [11].

The produced $\mathrm{SbMe}_{3}$ from the thermolysis of $\mathrm{Sb}_{2} \mathrm{Me}_{4}$ undergoes further decomposition above $400{ }^{\circ} \mathrm{C}$ to form a series of hydrocarbons including methyl radical, methane, and ethane. These species were reported during the thermolysis study of $\mathrm{SbMe}_{3}$ [24-26]. The formation of these species was attributed to the homolytic scission of the $\mathrm{Sb}-\mathrm{C}$ bond to release $\mathrm{CH}_{3}$ radical that further reacts following hydrogen abstraction or recombination to form a variety of hydrocarbons. The growth of carbon-free antimony films above $400{ }^{\circ} \mathrm{C}$ is expected to require the use of additional molecular hydrogen flow to facilitate the formation of methane as the major product of the thermolysis. This agrees with the investigation of Larson et al. [23, 24], who reported the decomposition threshold of $\mathrm{SbMe}_{3}$ at $400{ }^{\circ} \mathrm{C}$ in inert atmosphere with significant recombination to form $\mathrm{C}_{2}$ - and $\mathrm{C}_{3}$-species. The occurrence of radical recombination constitutes a high risk of carbon contamination, in that unsaturated hydrocarbons might form. The presence of $\mathrm{D}_{2}$ or $\mathrm{H}_{2}$ decreases the decomposition threshold to approximately $350{ }^{\circ} \mathrm{C}$ and suppresses the formation of $\mathrm{C}_{2}-$ and $\mathrm{C}_{3}$-species. $\mathrm{CH}_{3} \mathrm{D}$ was observed as the predominant decomposition product of $\mathrm{SbMe}_{3}$ in $\mathrm{D}_{2}$ atmosphere [23, 24].

\section{Tetraethyldistibine}

The mass spectrum obtained with $\mathrm{Sb}_{2} \mathrm{Et}_{4}$ at $30^{\circ} \mathrm{C}$ shows the presence of the expected precursor molecule and the corresponding electron-induced fragments: $\mathrm{Sb}_{2} \mathrm{Et}_{3}, \mathrm{Sb}_{2} \mathrm{Et}_{2}$, and $\mathrm{Sb}_{2} \mathrm{Et}$, in addition to fragments with one $\mathrm{Sb}$ atom. $\mathrm{Et}_{2} \mathrm{Sb}-\mathrm{O}-\mathrm{SbEt}_{2}$, the oxidation

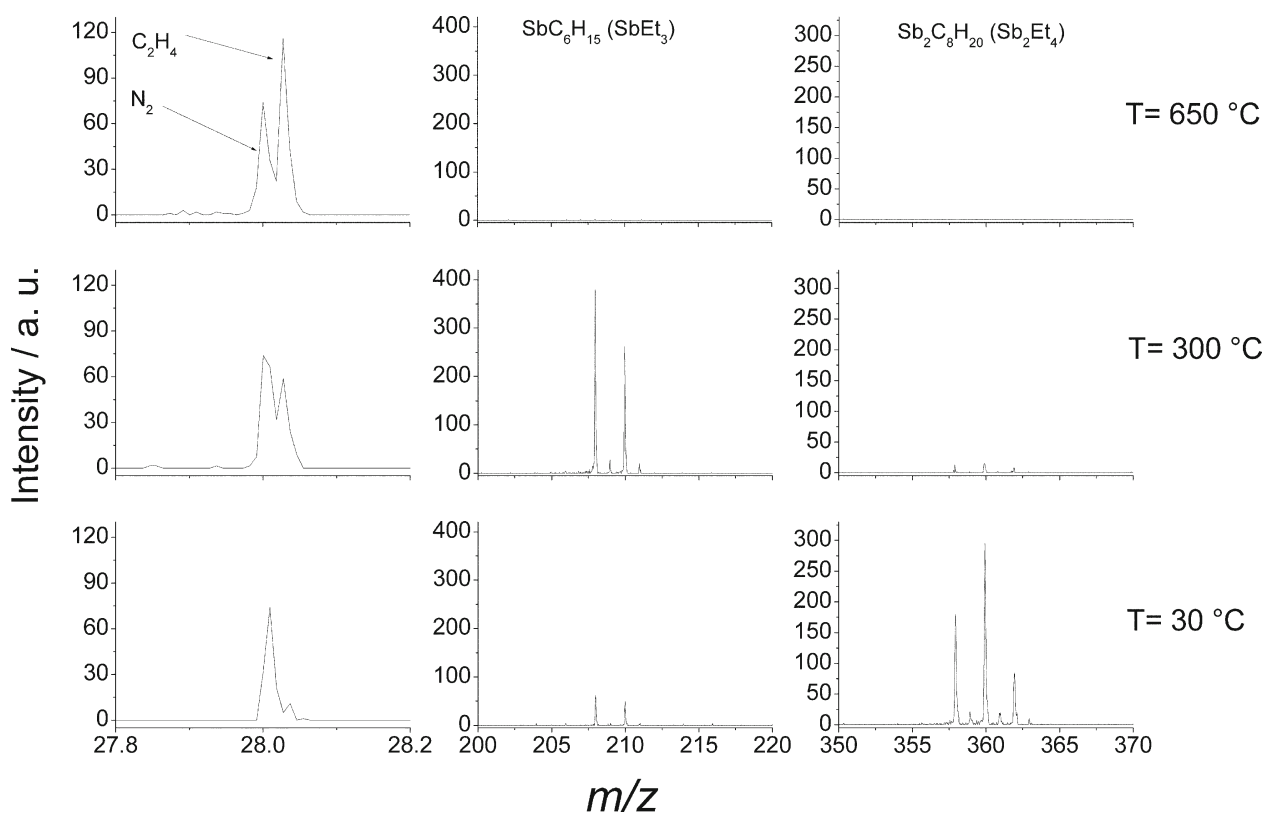

Figure 3. Mass spectra of $\mathrm{Sb}_{2} \mathrm{Et}_{4}$ collected after ionization with a $10 \mathrm{eV}$ electron beam, CVD reactor at 30,300 , and $650^{\circ} \mathrm{C}$. 
product of $\mathrm{Sb}_{2} \mathrm{Et}_{4}$, was also detected with a relatively low intensity. The formation of this molecule as reported by Breunig [22] and Dickson et al. [11], despite the taken precautions, shows the extremely high affinity of $\mathrm{Sb}_{2} \mathrm{Et}_{4}$ toward oxygen. The decomposition path of $\mathrm{Sb}_{2} \mathrm{Et}_{4}$ will be discussed while ignoring the presence of the small fraction of $\mathrm{Et}_{2} \mathrm{Sb}-\mathrm{O}-\mathrm{SbEt}_{2}$, with the assumption that no significant interaction takes place.

At the reactor temperature of $300{ }^{\circ} \mathrm{C}, \mathrm{Sb}_{2} \mathrm{Et}_{4}$ was almost completely thermally decomposed and molecules with a single antimony atom were formed. The relative intensities of the peaks attributed to $\mathrm{SbEt}_{3}$, $\mathrm{SbEt}_{2}$, and $\mathrm{SbEt}$ correspond to the reference spectrum of $\mathrm{SbEt}_{3}$, which is given as supplementary materials. Therefore, it is assumed that the decomposition of $\mathrm{Sb}_{2} \mathrm{Et}_{4}$ occurs with surface trapping of the reactive antimony-containing intermediates, as illustrated in Scheme 2. Above $650{ }^{\circ} \mathrm{C}$, no antimony-containing species were detected as depicted in Figure 3.

The temperature scan in Figure 4 a shows that reaction (2) is significantly observed starting at a temperature of $100{ }^{\circ} \mathrm{C}$ and is terminated at $300^{\circ} \mathrm{C}$. The activation energy of this reaction was calculated to be (104 \pm 7) $\mathrm{kJ} / \mathrm{mol}$ from the decay of the molecular peak with
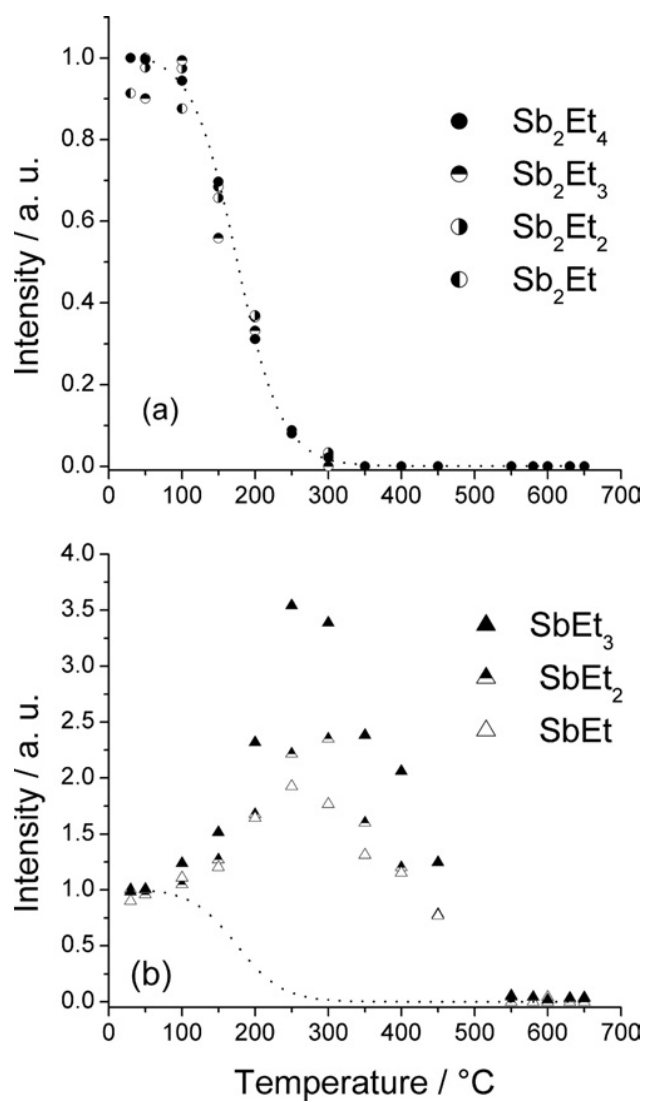

Figure 4. Temperature-dependent intensity of relevant antimonycontaining species in the thermolysis of $\mathrm{Sb}_{2} \mathrm{Et}_{4}$. The curve fitting the depletion of $\mathrm{Sb}_{2} \mathrm{Et}_{4}$ (upper diagram) is included with the profiles of the species containing one antimony atom (lower diagram). (a) $\mathrm{Sb}_{2} \mathrm{Et}_{4}$ and associated fragment ions; (b) $\mathrm{SbEt}_{3}$ intermediate and associated fragment ions.

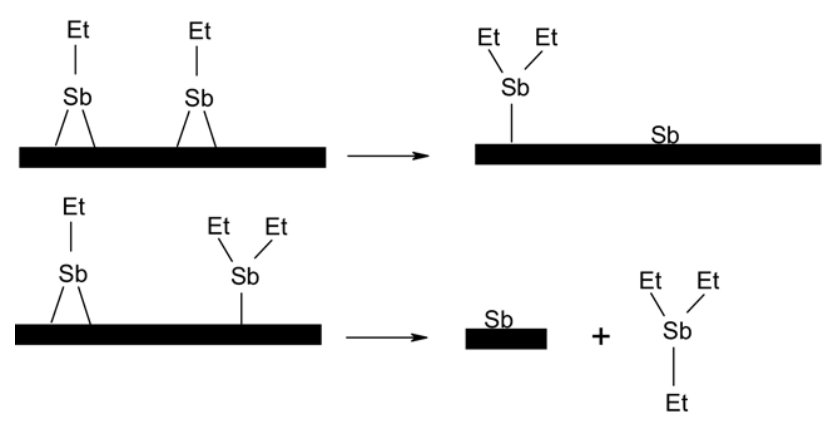

Scheme 3

increasing temperature. For this calculation, a firstorder kinetics and a preexponential factor of $\mathrm{A}=1 \times$ $10^{13} \mathrm{~s}^{-1}$ were assumed. A significant production of $\mathrm{SbEt}_{3}$ starts above $100^{\circ} \mathrm{C}$, as shown in Figure $4 \mathrm{~b}$, and attains its maximum at $250-300{ }^{\circ} \mathrm{C}$, which is the temperature of the complete depletion of $\mathrm{Sb}_{2} \mathrm{Et}_{4}$.

Examination of the evolution of low-mass peaks with increasing temperature does not show any significant production of hydrocarbons below $250^{\circ} \mathrm{C}$, which clearly indicates that the only product of reaction (2) is elemental antimony and $\mathrm{SbEt}_{3}$. This suggests the exchange of ethyl groups on the surface as illustrated in Scheme 3 as the dominant deposition mechanism at temperatures in the range of $100-250{ }^{\circ} \mathrm{C}$. Interestingly, Dickson et al. [11] noticed the degradation of $\mathrm{Sb}_{2} \mathrm{Et}_{4}$ in the liquid phase when exposed to daylight at temperatures as low as $50{ }^{\circ} \mathrm{C}$ to produce $\mathrm{SbEt}_{3}$ and metallic antimony deposit.

Our recent investigation shows that $\mathrm{SbEt}_{3}$ is remarkably stable up to a reactor temperature of $400{ }^{\circ} \mathrm{C}$ in similar conditions [21]. Therefore, the observed decay of the intensity of $\mathrm{SbEt}_{3}$ above $250{ }^{\circ} \mathrm{C}$ in Figure 4 cannot be attributed to its thermal decomposition. This result rather indicates that the path leading to the formation of $\mathrm{SbEt}_{3}$ became unfavorable at higher temperatures. It is concluded that a competing decomposition mechanism, with the reaction represented in Scheme 2, builds up at temperatures exceeding $250{ }^{\circ} \mathrm{C}$.

At temperatures above $250^{\circ} \mathrm{C}$, where the formation of $\mathrm{SbEt}_{3}$ is not favored, several hydrocarbons were detected with different trends as a function of the temperature. The presence of $n$-butane, ethene, ethane, and ethyl radical, shown in Figure 5, indicates the competing radical and molecular route for the release of the ligand from the surface. The radical route involves the scission of the $\mathrm{Sb}-\mathrm{C}$ bond and the formation of gas-phase ethyl radicals, whereas the molecular route involves the $\beta$-hydride elimination by releasing ethene and forming surface hydrogen. The surface hydrogen might react with an adjacent ethyl group to form ethane. Since no hydrogen was detected it is assumed that all hydrogen produced during the $\beta$-hydride elimination is used to form ethane. A recombinative desorption of adjacent ethyl groups leads to the formation of $n$-butane, which is detected in its molecular form, but 

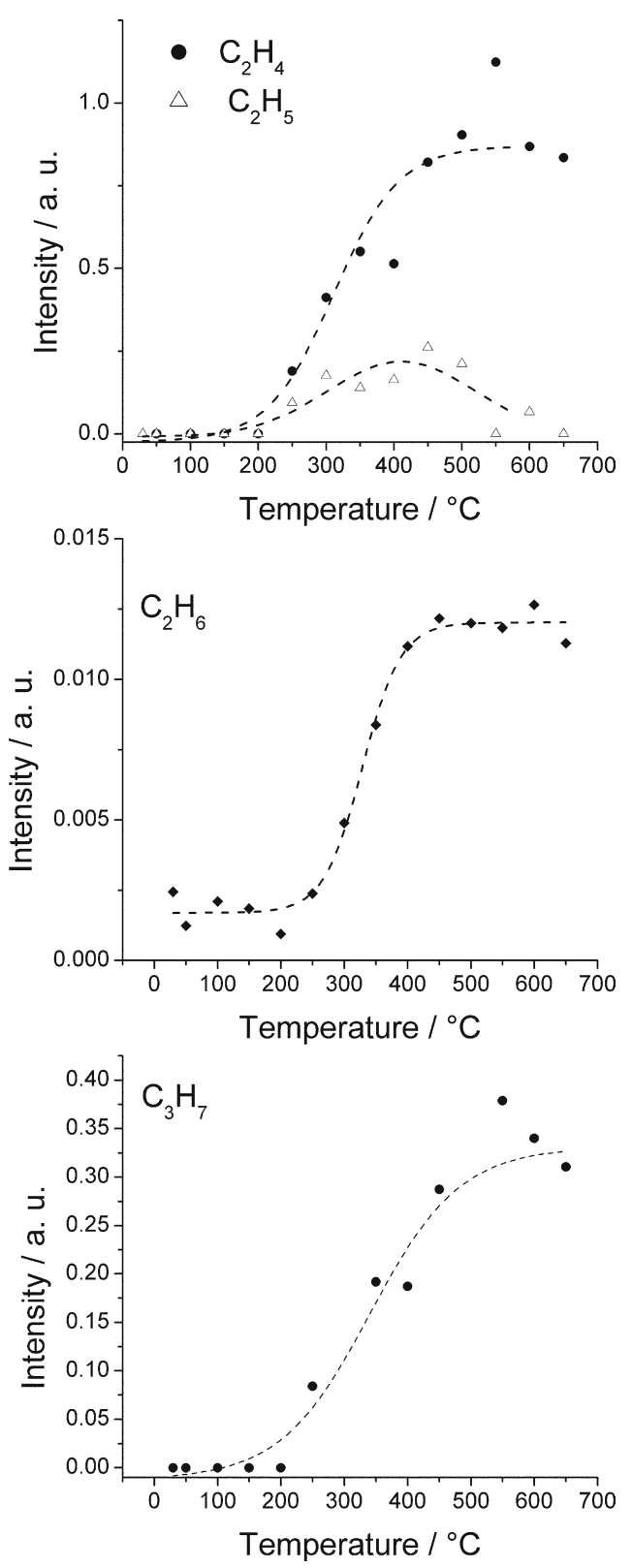

Figure 5. Temperature-dependent intensity of relevant produced hydrocarbon species. Ethene, ethyl radicals, and $\mathrm{C}_{3} \mathrm{H}_{7}$ (most intense fragment ion of $n$-butane) were measured using the ionization energy of $10 \mathrm{eV}$; whereas ethane, which was not detected at $10 \mathrm{eV}$ because of the low intensity (see supplementary materials), was measured with $20 \mathrm{eV}$.

also by its most intense fragment $\mathrm{C}_{3} \mathrm{H}_{7}$ during ionization at $10 \mathrm{eV}$ attributed to the energy spread [21]. From the relative intensities of ethene and ethyl radical, it can be concluded that the radical route is less favorable than the molecular route and it is observed in a limited temperature range.

A comparative study of the thermolysis of $\mathrm{Sb}_{2} \mathrm{Et}_{4}$ and $\mathrm{SbEt}_{3}$ shows a clear advantage of $\mathrm{Sb}_{2} \mathrm{Et}_{4}$ in terms of decomposition temperature and activation energy. Based on the mass spectrometric data, the possibility to grow antimony films using $\mathrm{Sb}_{2} \mathrm{Et}_{4}$ can be expected at a temperature of $100{ }^{\circ} \mathrm{C}$ with an activation barrier of 104 $\mathrm{kJ} / \mathrm{mol}$, which contrasts with $\mathrm{SbEt}_{3}$ that requires a temperature of $400{ }^{\circ} \mathrm{C}$ and presents a barrier of 183 $\mathrm{kJ} / \mathrm{mol}$ [21]. Regarding the decomposition mechanism, $\mathrm{Sb}_{2} \mathrm{Et}_{4}$ offers a wide temperature range of $100-250{ }^{\circ} \mathrm{C}$, where a clean reaction path is dominant that produces exclusively elemental $\mathrm{Sb}$ and $\mathrm{SbEt}_{3}$. The decomposition path above $250{ }^{\circ} \mathrm{C}$ is mainly dominated by a molecular route with formation of ethane, ethane, and $n$-butane. It is worth noting that these species were also observed during the thermolysis of $\mathrm{SbEt}_{3}$, but at temperatures exceeding $400{ }^{\circ} \mathrm{C}[21,26]$. Therefore, a carbon-free antimony film is expected when using $\mathrm{Sb}_{2} \mathrm{Et}_{4}$ as precursor.

\section{Conclusion}

The thermal behavior of two distibine compounds $\left(\mathrm{Sb}_{2} \mathrm{R}_{4}: \mathrm{R}=\mathrm{Me}\right.$, Et) was investigated under near-CVD conditions. Both precursors exhibit low decomposition temperature and activation energies when compared to traditional antimony sources, which was attributed to the occurrence of an intramolecular disproportionation reaction. The $\mathrm{Sb}_{2} \mathrm{Me}_{4}$ precursor exhibits a homogeneous intramolecular disproportionation to form gas-phase $\mathrm{SbMe}$ and $\mathrm{SbEt}_{3}$, whereas $\mathrm{Sb}_{2} \mathrm{Et}_{4}$ seems to undergo this reaction with a surface trapping of the reactive SbEt. These precursors offer a particularly convenient temperature range where the formed alkylstibinidine molecules that undergo ligand exchange on the hot surface to release $\mathrm{SbR}_{3}$ and form $\mathrm{Sb}$ deposit. This clean decomposition path is expected to enable the growth of pure films at low temperature and might be considered as a strategy for other elements. Further investigations on the surface reactions and on CVD deposition of $\mathrm{Sb}$ films are suggested.

\section{Acknowledgments}

The authors gratefully acknowledge financial support by the Deutsche Forschungsgemeinschaft in the context of the Priority Program (Schwerpunktprogramm) 1119.

\section{References}

1. Snyder, G. J.; Toberer, E. S. Complex Thermoelectric Materials. Nat. Mater. 2008, 7, 105-114.

2. Liu, T. X.; Tang, X. F.; Xie, W. J.; Yan, Y. P.; Zhang, Q. J. Crystal Structures and Thermoelectric Properties of Sm-Filled Skutterudite Compounds $\mathrm{Sm}_{\mathrm{y}} \mathrm{Fe}_{\mathrm{x}} \mathrm{Co}_{4-\mathrm{x}} \mathrm{Sb}_{12}$. J. Rare Earths 2007, 25, 739-743.

3. Khandekar, A. A.; Yeh, J. Y.; Mawst, L. J.; Song, X.; Babcock, S. E.; Kuech, T. F. Effects of Ga- and Sb-Precursor Chemistry on the Alloy Composition in Pseudomorphically Strained $\mathrm{GaAs}_{1-\mathrm{y}} \mathrm{Sb}_{\mathrm{y}}$ Films Grown via Metalorganic Vapor Phase Epitaxy. J. Crystal Growth 2007, 303, 456-465.

4. Cheng, X. C.; McGill, T. C. Molecular Beam Epitaxy Growth of Antimonide Avalanche Photodetectors with InAs/AlSb Superlattice as the n-Type Layer. J. Crystal Growth 2000, 208, 183-188.

5. Flatte, M. E. Semiconductor Physics: Relativity on a Chip. Nature 2004, $427,21-22$.

6. Deakin, L.; Mar, A. Magnetic Properties and Magnetoresistance of $\mathrm{GdCrSb}_{3}$. Chem. Mater. 2003, 15, 3343-3346.

7. Gratzel, M. Materials Science: Ultrafast Colour Displays. Nature 2001, 409, 575-576.

8. Todd, M. A.; Bandari, G.; Baum, T. H. Synthesis and Stabilization of Stibine for Low-Temperature Chemical Vapor Deposition of CarbonFree Antimony Films. Chem. Mater. 1999, 11, 547-551. 
9. Behet, M.; Stoll, B.; Heime, K. Composition-Study on the Low-Pressure Metalorganic Vapor-Phase Epitaxial-Growth of InSb on GaAs with Trimethylantimony and Triethylantimony as Sb Precursor. J. Crystal Growth 1994, 135, 434-440.

10. Egan, R. J.; Chin, V. W. L.; Tansley, T. L. Growth, Morphology and Electrical-Transport Properties of MOCVD-Grown P-InSb. Semicond. Sci. Technol. 1994, 9, 1591-1597.

11. Dickson, R. S.; Heazle, K. D.; Pain, G. N.; Deacon, G. B.; West, B. O.; Fallon, G. D.; Rowe, R. S.; Leech, P. W.; Faith, M. Antimony Sources for MOCVD: The Use of $\mathrm{Et}_{4} \mathrm{Sb}_{2}$ as a P-Type Dopant for $\mathrm{Hg}_{1-\mathrm{x}} \mathrm{Cd}_{\mathrm{x}} \mathrm{Te}$ and Crystal Structure of the Adduct $\left[\mathrm{Et}_{4} \mathrm{Sb}_{2} \cdot 2 \mathrm{CdI}_{2}\right]$. J. Organomet. Chem. 1993, 449, 131-139.

12. Pain, G. N. Method for the Deposition of Group 15 and/or Group 16 Elements 1992. WO Patent/1992/009719.

13. Schulz, S. The Chemistry of Group 13/15 Compounds (III-V Compounds) with the Higher Homologues of Group 15, Sb and Bi. Coord. Chem. Rev. 2001, 215, 1-37.

14. Skulan, A. J.; Nielsen, I. M. B.; Melius, C. F.; Allendorf, M. D. BAC-MP4 Predictions of Thermochemistry for Gas-Phase Antimony Compounds in the Sb-H-C-O-Cl system. J. Phys. Chem. A 2006, 110, 5919-5928.

15. Leech, P. W.; Heazle, K. D.; Deacon, G. B.; Dickson, R. S.; West, B. O.; Faith, M.; Frost, C. R. p-Type Doping of $\mathrm{Hg}_{0.4} \mathrm{Cd}_{0.6} \mathrm{Te}$ Using $\mathrm{Et}_{4} \mathrm{Sb}_{2}$. J. Crystal Growth 1994, 139, 247-250.

16. Breunig, H. J.; Breuniglyriti, V.; Knobloch, T. P. Simple Synthesis of Tetramethyldistibane and Tetraethyldistibane. Chem.-Ztg. 1977, 101, $399-400$.

17. Meinema, H. A.; Martens, H. F.; Noltes, J. G. Investigations on Organoantimony Compounds. 9. Antimony-Carbon Bond Cleavage in Trialkylstibines by Sodium in Liquid-Ammonia-Synthetic Applications of Dialkylstibines by Sodium and Diphenylstibylsodium. J. Organomet. Chem. 1973, 51, 223-230.

18. Schulz, S.; Fahrenholz, S.; Kuczkowski, A.; Assenmacher, W.; Seemayer, A.; Hommes, A.; Wandelt, W. Deposition of GaSb films from the single-source precursor [t-Bu2GaSbEt2](2). Chem. Mater. 2005, 17, 1982-1989.

19. Schulz, S.; Fahrenholz, S.; Schuchmann, D.; Kuczkowski, A.; Assenmacher, W.; Reilmann, F.; Bahlawane, N.; Kohse-Höinghaus, K. Single source precursor-based HV-MOCVD deposition of binary group 1 13-antimonide thin films. Surf. Coat. Technol. 2007, 201, 9071-9075.

20. Haase, T.; Kohse-Hoinghaus, K.; Bahlawane, N.; Djiele, P.; Jakob, A.; Lang, H. CVD with Tri-(n)butylphosphine Silver(I) Complexes: Mass Spectrometric Investigations and Depositions. Chem. Vapor Deposit. 2005, 11, 195-205.

21. Bahlawane, N.; Reilmann, F.; Salameh, L.-C.; Kohse-Hoinghaus, K. Mass-Spectrometric Monitoring of the Thermally Induced Decomposition of Trimethylgallium, Tris(tert-butyl)gallium and Triethylantimony at Low-Pressure Conditions. J. Am. Soc. Mass Spectrom. 2008, 19, 947-954.

22. Breunig, H.; Kruger, T.; Lork, E. Oxidation of Tetraaryldistibanes: Syntheses and Crystal Structures of Diarylantimony Oxides and Peroxides, $\left(\mathrm{R}_{2} \mathrm{Sb}\right)_{2} \mathrm{O},\left(\mathrm{R}_{2} \mathrm{Sb}\right)_{4} \mathrm{O}-6$ and $(\mathrm{R} 2 \mathrm{SbO})(4)(\mathrm{O}-2)(2)(\mathrm{R}=\mathrm{Ph}, \mathrm{o}-\mathrm{Tol}$, p-Tol). J. Organomet. Chem. 2002, 648, 209-213.

23. Jackson, D. A. Influence of Carrier Gases on Pyrolysis of Organometallics. J. Crystal Growth 1989, 94, 459-468.

24. Larsen, C. A.; Li, S. H.; Stringfellow, G. B. Decomposition Mechanisms of Trimethylantimony and Reactions with Trimethylindium. Chem. Mater. 1991, 3, 39-44.

25. Svoboda, G. D.; Gleaves, J. T.; Mills, P. L. New Method for Studying the Pyrolysis of VPE CVD Precursors under Vacuum Conditions: Application to Trimethylantimony and Tetramethyltin. Ind. Eng. Chem. Res. 1992, 31, 19-29.

26. Berrigan, R. A.; Metson, J. B.; Russell, D. K. Radical and Molecular Processes in the Thermal Decomposition of Trimethyl and Triethyl Stibines. Chem. Vapor Deposit. 1998, 4, 23-28. 